\title{
Complementarities of Knowledge Worker Productivity: Insights from an Online Experiment of Software Programmers with Innovative Cognitive Style \\ Natallia Pashkevich ${ }^{1}$ and Darek M. Haftor ${ }^{2,3}$
}

ABSTRACT

The literature has been inconclusive regarding which factors determine knowledge worker productivity. To remedy that gap, this paper presented an online experiment to measure the productivity of software programmers, as a representative of knowledge workers, in a particular situation when a more aligned with the work process IT system is used. The assumed research model was based on the systems approach of complementarity theory and combined the following factors: worker's cognitive style, work process, decision-making authority, worker training mode, and worker incentive. The experiment was conducted for 4 months and attracted 110 participants with innovative cognitive style from two crowdsourcing platforms. The results demonstrate that complementarities condition the productivity of a knowledge worker. More specifically, the learning effect is crucial for productivity gains and should be considered in further detail in the design of new studies. The paper's key contribution is the test of a unique configuration of two systems of complementary factors, because most of the literature has investigated only the impact of particular factors in isolation.

KEY WORDS: complementarity theory, individual productivity, knowledge worker, online experiment, software programmer.

JEL Classification: C90, M15, O33.

'Södertörn University, Sweden

¿Uppsala University, Sweden

${ }^{3} U$ niversity of Economics and Human Sciences in Warsaw, Poland

\section{Introduction}

Productivity of an organization is at the core of organizational economics (Leoni, 2013) and the theory of the firm (Roberts, 2007). Microeconomists have long studied the function of an organization in its market; however, the relatively recent field of organizational economics attempts to open the black-boxed organization of microeconomic studies to identify its eco-

Correspondence concerning this article should be addressed to: Natallia Pashkevich, Södertörn University, Sweden. E-mail: natallia.pashkevich@sh.se nomic mechanisms and their functioning (Gibbons \& Roberts, 2013). A key approach to that end rests on the notion of complementarities (Bloom et al., 2010; Brynjolfsson \& Milgrom, 2013), that is, factors that can be synchronized to create a system that manifests a superior performance (Milgrom \& Roberts, 1990). Notably, the question of what factors should be synchronized and how these factors should be synchronized to generate a local productivity optimum remains, to a large extent, underexplored (Brynjolfsson \& Milgrom, 2013).

Although the literature has identified stable sets of complementarities for conventional industrial or- 
ganizations (Brynjolfsson \& Hitt, 2003; Bugamelli \& Pagano, 2004; Milgrom \& Roberts, 1995), only initial research on the complementarities of modern knowledge organizations (Aral et al., 2012; Athey \& Stern, 2002; Autor et al., 2003) that has assumed an atomistic-level focus on individual workers (Foss, 2005; Schumpeter, 1909), their work streams, and tools employed has been performed.

This study assumed the atomistic approach because knowledge work is not executed by an organization but by its knowledge workers who pursue various workflows and use work tools, namely, IT systems (Palvalin et al., 2013; Pyöriä, 2005). We assumed that the results from studies at the organizational and individual levels can be combined to improve the comprehensive understanding of systems of organizational complementarities. The two questions targeted are as follows. Which complementary factors must be synchronized to induce to productivity gains of a knowledge worker who uses an IT system? How should these factors be synchronized?

The focus on the productivity of a knowledge worker's use of IT systems has been debated due to the revival of the so-called productivity paradox (Aral et al., 2012; Chung \& Hossain, 2009; Jain \& Kanungo, 2005, 2013; Palvalin et al., 2013; Wu et al., 2009; Webster, 2012), originally coined by Robert Solow in the 1980s (Solow, 1987). Studies at the levels of an economy (Arvanitis \& Loukis, 2009; Dedrick et al., 2013; Jorgenson, 2007), an industry (Han et al., 2011; Hu \& Quan, 2005), and an organization (Kohli \& Grover, 2008; Tambe et al., 2012) have demonstrated that when certain complementary factors are synchronized in a particular manner, including the use of IT systems, superior productivity may be achieved.

At the level of an individual knowledge worker, few studies have presented heterogeneous insights (Aral et al., 2012; Athey \& Stern, 2002; Autor et al., 2003). The first two earlier studies have demonstrated that productivity gains when knowledge workers use an IT system may require complementary factors such as the work process (Athey \& Stern, 2002; Autor et al., 2003). The latter study suggested that complementary factors may have a contingent relationship between a knowledge worker's use of an IT system and a work process (Aral et al., 2012). Overall, all three studies have assumed a narrow system of complementary factors by testing only a few factors: the use of an IT system by knowledge workers and the work process. This narrow approach has disregarded other factors identified in the literature regarding conditioning the productivity of knowledge workers (e.g. Drucker, 1999; Hopp, et al., 2009; Mason \& Mitroff, 1973; Reinhardt et al., 2011; Kianto et al., 2018). This study explored this limitation in the context of knowledge workers' productivity by assuming a broader approach that accounts for several other factors that demonstrate complementarity with each other.

This study addressed the productivity of a software programmer, perhaps the contemporary icon of a knowledge worker, whose job description is to digitalize our societies (Hernández-López et al., 2015). The demand trend for software programmers is increasing (Sliwa, 2018); thus, their increasing share of the total cost structure has made the question of their productivity a key managerial issue (MuratbekovaTouron \& Galindo, 2018).

This study tested the productivity of an innovative cognitive style of a software programmer being synchronized with two complementarity setups, namely, stable and dynamic, in an online experiment with 110 subjects. These setups included a specific type of work process, training, incentive, and decisionmaking mode in a situation where a new IT system aligned with the work process is used by the programmer, compared with a nonaligned IT system.

The results of the experiment suggest the following: (a) software programmers with innovative cognitive style demonstrate different productivity outcomes when involved in either a stable or dynamic complementarity setup and, thus, provide support for the systems approach of complementarity theory; (b) learning effects are central to productivity and thus further research should include a longer learning curve before and after an aligned IT system is introduced, and (c) a certain trade-off exists between the work time and work output quality of a software programmer and must be closely monitored to understand the impact of complementarity factors and optimal trade-offs between them.

The results of this study indicate that complementary factors are critical at the level of an individual 
knowledge worker who uses an IT system and the need to investigate in greater detail which factors should be synchronized and how to optimize productivity of an individual knowledge worker. This study suggests which factors to consider for the configuration of a system of complementarities for worker productivity and contributes to the literature by expanding the prevailing narrow approach of the system of complementarities into a broader approach, thereby making greater justice to real life conditions, which provides initial managerial suggestions regarding which factors condition knowledge worker productivity.

The disposition of this paper is as follows. To complete this introduction, a presentation of the theoretical background and hypotheses development follows. The remainder of the paper presents the method, results, discussion, and conclusion.

\section{Theoretical background}

Factors of an organization may affect each other in three ways: independent, substitutive, and complementary (Parmigiani \& Mitchell, 2009). An independent relationship exists when a change in the level of one element does not affect the value of another element. A substitution relationship exists when an increasing value of one element weakens the value of another element. A complementary relationship exists when a change in the level of one element enlarges the impact of another element. In this study, we draw on complementarity theory, which is based on the assumptions from contingency and configuration

Table 1. Foundation for the Complementarity Setups Development

\section{Variables used}

\begin{tabular}{|c|c|c|c|c|c|}
\hline Study & IT use & $\begin{array}{l}\text { Operational } \\
\text { task/process }\end{array}$ & $\begin{array}{l}\text { Individual } \\
\text { factors }\end{array}$ & $\begin{array}{l}\text { Organizational } \\
\text { factors }\end{array}$ & Obtained/expected results \\
\hline Athey \& Stern, 2002 & Yes & Yes & No & No & $\begin{array}{l}\text { Knowledge worker's use of } \\
\text { structured work process and } \\
\text { the use of an IT system are not } \\
\text { complementary }\end{array}$ \\
\hline Autor et al., 2003 & Yes & Yes & No & No & $\begin{array}{l}\text { Knowledge worker's nonrou- } \\
\text { tine work process is comple- } \\
\text { mentary to the use of an IT } \\
\text { system }\end{array}$ \\
\hline Aral et al., 2012 & Yes & Yes & No & No & $\begin{array}{l}\text { Knowledge worker's work } \\
\text { process in terms of its intensity } \\
\text { of multiproject work is comple- } \\
\text { mentary to the use of an IT } \\
\text { system }\end{array}$ \\
\hline This study & Yes & Yes & Yes & Yes & $\begin{array}{l}\text { A full set of complementari- } \\
\text { ties when matched correctly } \\
\text { to the use of an IT system can } \\
\text { increase individual productivity }\end{array}$ \\
\hline
\end{tabular}


theories and considers an organization as a system of interdependent individual, organizational, and strategic elements (Roberts, 2007). This theory implies that a set of theoretical constructs must be allocated into a system of factors, where each factor is related in a particular manner to the other factors such that systemic properties can emerge, which induces greater productivity (Milgrom \& Roberts, 1990, 1995).

At the level of an individual worker, and in the context of a knowledge worker that uses an IT system to conduct work processes, complementarity theory has been applied in three studies. In the first study, the structure of the work process, where well-structured versus nonstructured work processes were compared, was assumed to complement IT use (Athey \& Stern, 2002). Notably, this study found that demonstrating productivity gains from those complementary factors was difficult. The second study explored the complementary relationship between the use of an IT system and two alternative work processes (Autor et al., 2003) and demonstrated that IT use is a strong complementary factor to only nonroutine tasks, rather than simple routine tasks. The third study (Aral et al., 2012) indicated that knowledge worker productivity is positively conditioned by the interaction between workers' IT use and type of work process; in this case, the intensity of multitasking is defined as the degree of worker's switch between work projects. Table 1 provides a summary of these three studies.

Complementarity theory has two investigative approaches: the interaction approach and systems approach (Ennen \& Richter, 2010). The interaction approach assumes a complementary relationship between a limited number of clearly identified factors, and the systems approach explores the impact of a system of multiple factors on performance outcomes. The three aforementioned studies employ the interaction approach, which has an obvious limitation regarding finding complementary relationships due to a limited number of factors (Ennen \& Richter, 2010). Additionally, the literature on knowledge worker productivity has recognized that individual productivity is a function of factors, including IT tools, work processes, and individual and work settings (Wojtczuk-Turek, 2017; Hopp et al., 2009; Reinhardt et al., 2011). As a consequence, this study assumed the systems approach to formulate hypotheses of potential complementary factors that, when matched correctly, can significantly affect productivity.

\section{Hypotheses Development}

The systems approach to complementary factors assumed in this study requires accounting for a larger set of complementary factors than the three aforementioned studies had accounted for (Ennen \& Richter, 2010). On the one hand, little indication was provided regarding which factors should be included and synchronized (Hopp et al., 2009; Palvalin et al., 2013); on the other hand, studies have tested for one factor or limited interactions among a few factors (Antikainen \& Lönnqvist, 2006; Baer et al., 2003; Cequea et al., 2011; Morgeson \& Humphrey, 2006; Singh \& Mohanty, 2012).

This study assumed only selected factors from the literature, without aiming to uncover novel, untested factors, to reduce the risks of failure of the complementarity setups developed. This study tested the research model on one type of knowledge worker, namely, a software programmer, because the literature has investigated the factors that condition software programmer productivity and provided several factors for programmers (Chilton et al., 2005; de Barros Sampaio, et al., 2010; Graziotin et al., 2014; Tonelli et al., 2013; Hernández-López et al., 2015; Jiang et al., 2007; Tomaszewski \& Lundberg, 2005; Trendowicz \& Münch, 2009), which is not the case with other professions. Additionally, the complementarity setups proposed in this study are too premature to be tested on a variety of types of knowledge workers. Finally, software programmer is a critical and growing profession (Sliwa, 2018) that has manifested a growing share of the total cost structure of many firms; therefore, effective productivity management of software programmers is of significant concern.

Based on the systems approach, we proposed a conceptualization of programmers' work to be understood in terms of the personal cognitive characteristics of programmers, characteristics of the work process, and organization settings in relation to individual productivity when an aligned IT system is used. The factors we used include elements from Kirton's adaption-innovation theory (Kirton, 1976, 1994, 2003) and literature on the work process and managerial practices (Bloom \& 
van Reenen, 2011; Edwards, 1991; Kristof-Brown \& Guay, 2011; Kristof, 1996; MacCormack et al., 2001; Staniewski, 2011); additionally, we formulated two complementarity setups of complementary factors, namely, stable and dynamic, that we further tested in a web-based online experiment where the subjects' task was to construct software from a received software specification (Table 2).

The essential component of software programmer productivity is the programmer who receives requirement specifications and produces a piece of software. A software programmer is a professional whose key act of information processing is conducted through cognitive faculties (Pyöriä, 2005), implying that human cognition is a central factor of information processing. In the psychological literature, cognitive characteristics have been shown to influence information processing ability (Agor, 1984; Rowe \& Mason, 1987).

This study adopted the Kirton scheme of adoption-innovation (Kirton, 1976, 1994), which holds that human cognition is characterized along a spectrum from adaptive to innovative information processing behavior. Individuals with an adaptive cognitive style tend to operate in a systematic and well-structured manner and prefer explicit and stable situations. By contrast, individuals with in- novative cognitive styles tend to operate in an ad hoc and creative manner with limited predefined structures. The Kirton scheme is adopted because studies have shown that cognitive styles condition different behavior in an individual, including problem-solving, depending on the context and its conditions (Kirton, 1994). This scheme is also the most explored and well-tested categorization of human cognitive styles (Brown, 2001).

A professional software programmer executes tasks that constitute a work process (Kock \& McQueen, 1996). The literature has demonstrated that the character of a work process influences the performance of a knowledge worker (Amabile, 1996; Keen \& Scott-Morton, 1978). This study assumed the distinction between a stiff and more flexible work process would affect performance outcomes (MacCormack et al., 2001). A stiff work process is predetermined and comprises activities, inputs, and outputs, whereas a flexible work process provides more freedom, that is, fewer details are imposed regarding what to do and how to do it (Abdolmohammadi \& Wright, 1987). According to the Kirton scheme (Kirton, 1994), to improve performance, a stiff work process should be conducted by an adaptive cognitive style programmer, and a flexible work process should be performed by an innovative cog-

Table 2. Complementarity Factors and Their Value Range Employed in This Study and Partly Tested in a Situation When a More Aligned IT System is Used

\begin{tabular}{ll} 
Complementarity setups and factors $\quad$ Value range \\
\hline
\end{tabular}

Cognitive style

Complementarity setup

Work process

Training mode

Incentive mode

Decision-making mode
Adaptive

Stable

Stiff

Push

Exogenous

High centralization
Innovative

Dynamic

Flexible

Pull
Endogenous

High decentralization 
nitive style programmer. These factors should complement each other in relation to the productivity in a manner that any alternative pairing of the two factors may not produce productivity increase.

A software programmer depends on their skillful use of work technologies (Webster, 2012). The mastery of such technology influences work productivity (Hitt \& Brynjolfsson, 1997) and may be supported by training (Hayes \& Allinson, 1998). Studies have established the significance of knowledge worker training, which advances cognitive ability to improve the performance of work tasks (Berings et al., 2005; Hayes \& Allinson, 1998; Sadler-Smith \& Smith, 2004). Additionally, the cognitive character of an individual corresponds to the training form (Amabile, 1996).

This study attempted to consider this complementarity and proposed that a programmer's training can have two modes. The first mode stipulates that well-structured training is mandatory prior to the use of work technologies; we call this form push-mode training. The second form of training is received on-demand and optionally, that is, prior to the use of work technology and after; we call this mode pull-mode training. We also hypothesized, based on the Kirton scheme (Kirton, 1994), that push-mode training complements the high productivity performance of a software programmer with an adaptive cognitive style, whereas pull-mode training complements the high productivity of a software programmer with an innovative cognitive style.

Motivation is one of the most well-researched factors that conditions a worker's productivity (Frey \& Osterloh, 2002; Kasof et al., 2007). The psychological literature has established a fundamental difference between exogenously and endogenously induced worker motivation (Amabile, 1996). This literature has demonstrated that the high performance of an adaptive cognitive style is matched with a greater degree of exogenous motivation, whereas the high performance of an innovative cognitive style shows a greater fit with endogenously induced motivation (Amabile et al., 1994; Baer et al., 2003). Therefore, we assumed that exogenous motivation complements the adaptive cognitive style and endogenous motivation complements the innovative cognitive style.

The last central area of software programmer productivity was associated with worker freedom, autonomy, or self-management (Zabojnik, 2002); operationally, this may be translated into decisionmaking freedom (Kozlowski \& Bell, 2003). Decision-making, a cognitive act, is central for many knowledge-intensive jobs (Hunt et al., 1989; Rowe \& Boulgarides, 1992) and has a significant impact on individual productivity (Ahearne et al., 2005; Baer et al., 2003). The literature has demonstrated complementarity between the decision-making authority, that is, centralization versus decentralization, and an individual's cognitive style (Amabile, 1996; Axtell et al., 2000; Oldham \& Cummings, 1996). A higher degree of centralization provides a software programmer with fewer decisions; thus, a greater number of guidelines should constitute a complement to an adaptive cognitive style (Baer et al., 2003). By contrast, a higher degree of decentralization offers a software programmer more freedom to decide how to act and change actions and should constitute a complement to an innovative cognitive style (Axtell et al., 2000; Oldham \& Cummings, 1996).

Considering all these factors, this study formulated two complementarity setups. A stable complementarity setup assumes that greater productivity can be expected when individuals with an adaptive cognitive style are matched with a complementarity setup that includes a stiff operating process, pushmode training in work technology, exogenous incentives, and centralized decision-making, compared with other configurations of these factors when an aligned IT system is used. By contrast, a dynamic complementarity setup assumes that greater productivity can be expected when individuals with an innovative cognitive style are matched with a complementarity setup that includes a flexible operating process, a combination of minor upfront mandatory training and optional on-demand training in work technology, endogenous incentives, and decentralized decision-making, compared with other configurations of these factors when an aligned IT system is used.

The innovators and adaptors must be tested for stable and dynamic setups to determine the feasi- 
bility of the proposed complementarity setups. Notably, this study tested only for innovators for each complementarity setup, and a further investigation is planned to test for adaptors for each setup. The following two hypotheses are tested in this experiment.

Hypothesis 1: Individuals with innovative cognitive style generate lower productivity (in terms of higher time and lower quality of the developed piece of software) when matched with a stable complementarity setup that includes a stiff operating process, push-mode training in work technology, exogenous incentives, and centralized decisionmaking, compared with other configurations of these factors when an aligned IT system is used, versus a nonaligned IT system.

Hypothesis 2: Individuals with innovative cognitive style generate higher productivity (in terms of lower time and higher quality of the developed piece of software) when matched with a dynamic complementarity setup that includes a flexible operating process, a combination of minor upfront mandatory training with optional on-demand training in work technology, endogenous incentives, and decentralized decision-making, compared with other configurations of these factors when an aligned IT system is used, versus a nonaligned IT system.

\section{Method}

The literature on complementarities has demonstrated that experimental studies are the most appropriate for an investigation of their effect on productivity (Brynjolfsson \& Milgrom, 2013; Camerer \& Weber, 2013; Gupta et al., 2018). Online controlled experiments have become a popular tool among scientists (Arechar et al., 2018; Hewson \& Stewart, 2016). The literature has indicated satisfactory reasons for choosing an online experiment as a research tool, including (a) reduced influence of experimenter expectancy on the participants' behavior and increased generalizability due to wider population access (Buchanan, 2002); (b) increased uniformity of the experimental procedure across participants, and participants' comfort due to 24-h access (Reips, 2002); and (c) reduced time spent on the experiment and associated costs (Birnbaum, 2004). Studies have also shown that the results of online experiments are consistent with traditional laboratory experiments (Arechar et al., 2018; Dandurand et al., 2008).

We designed an online experiment to fulfill the following criteria: (a) individuals with innovative cognitive styles are proportionally involved in stable and dynamic complementarity setups during all sessions, (b) complementary factors identified in the literature are operationalized and mirrored real work settings, (c) subjects chosen for the experiment are familiar with the topic of this study and appropriate for the experiment (Camerer \& Weber, 2013), and (d) sample size is expected to be sufficiently large to provide the statistical power of the test.

\subsection{Experimental Design and Procedure}

To test whether a set of matched complementary factors affect programmer productivity in relation to cognitive style when two IT systems are used, namely, one nonaligned IT system and one aligned IT system with the work process, a dedicated website was developed and available online for 4 months (October 2015-January 2016). We expected that innovators involved in a dynamic complementarity setup, rather than innovators in stable complementarity setup, have productivity advantages when an aligned IT system is used (Table 3 ).

The experiment comprised three sessions: Each session represented an assignment that concerned the development of animation, a to-do list, and text analysis software. Four professional programmers tested the content and functionality of the online version of the experiment and reported the uniformity of the assignments' complexity. The first session was conducted to establish a benchmark: participants developed a software application by using a text editor, which represents a nonaligned IT system. In the second session, an aligned IT system, Cloud9 (an online integrated development environment), that provides comprehensive functionality for software development was used in a synchronized manner with a cognitive style and complementarity setups. We designed the third session to account for a learning-curve effect (McLeod et al., 2008; Womer, 1984). This session also included 
Table 3. Experimental Design and the Expected Results

\begin{tabular}{lcccc}
\hline Cognitive style & $\begin{array}{c}\text { Complementarity } \\
\text { setup }\end{array}$ & $\begin{array}{c}\text { Session 1 } \\
\text { (nonaligned IT) }\end{array}$ & $\begin{array}{c}\text { Session 2 } \\
\text { (aligned IT) }\end{array}$ & $\begin{array}{c}\text { Session 3 } \\
\text { (learning effect) }\end{array}$ \\
\hline Innovative & Stable & Loss & Loss & Loss \\
Innovative & Dynamic & Gain & Gain & Gain
\end{tabular}

an aligned IT system and the same complementarities as the second session. Each session had identical time frames (between 20 minutes and 1 hour) and a slight variation of the assignment with an equal level of complexity. Voluntary participation in the experiment was incentivized by providing a minor payment. The measures of productivity used to evaluate the developed product were the time taken by participants to complete each session, completeness regarding how many of the functional requirements were completed, and correctness (how well the functional requirements were implemented) of the application developed.

The experimental procedure started with a questionnaire available online to identify the so-called KAI index (Kirton, 1976), which determined whether the individual had an innovative or an adaptive cognitive style and collected demographic control variables. After identification of the cognitive style, the experimental sessions were performed. Productivity of software programmers was measured at three time points after each session was completed. When the data collection process finished, the questionnaires and productivity data were analyzed.

\subsection{Operationalization of the Main Constructs}

The main independent constructs of the experiment were an IT system, the cognitive style of an individual software programmer, the work process structure, the type of training, the worker's incentives, and the decision-making structure. During the first session, the participants used a generic text editor (Notepad) that represented a nonaligned IT system to build code, and a web browser to run the code. During the second and third sessions, an aligned IT system was deployed and used. This IT system is an Integrated Development Environment Cloud9 with many supportive features for software programming, including pre-setup workspaces, code completion, color highlighting, automatic code reformatting, navigation, and debugging. We used this tool to ensure the participants could work in a realistic professional environment.

We used a questionnaire to identify the KAI index (Kirton, 1976) of whether an individual has an adaptive or innovative cognitive style. This KAI index is measured based on a 32 -item instrument with a 5 -point scale, in which participants indicate on a scale from Strongly disagree to Strongly agree to present their type of cognitive style. An overall KAI score has a theoretical mean of 96; below this score, individuals are considered adaptors, and above this score, as innovators.

Animation, to-do list, and text analysis assignments were developed to represent the stiff and flexible work process structures to satisfy two key criteria: (a) whether the requirement specification for the assignment was fully comprehensive and (b) whether any modification of the requirement specification was made during the software development process. Based on these criteria, the process was defined as stiff when fully comprehensive (the requirement specification document is perfectly specified regarding all the key aspects of the software to be developed) and no modifications had to be made to the requirement specification during the process of software development. In the flexible process, the requirement specification was partially completed, that is, a software programmer had to make assumptions on their own. In addition, during the flexible process, modifications to the requirements' specifications were provided.

Before the second session, the participants received a corresponding type of training in the use of Cloud9 regarding a particular complementarity setup. The stable complementarity setup group received informa- 
tion regarding the main features of Cloud9, namely, code completion, automatic code formatting, code navigation, and visualizing code documentation, and received links to two introductory videos about how to get started and create a workspace with Cloud9. The participants involved in a dynamic complementarity setup also received basic information about the main features of Cloud9 and a recommendation to watch short videos, if necessary, during the performance of the assignments.

All the participants received USD 30 as a participation incentive, to limit dropout, and reflect working reality when employees receive a salary for job performance. In the second and third sessions, the stable complementarity setup group received messages indicating that when the assignments were complete, they would receive their rating and assessment as nonfinancial extrinsic rewards (Armstrong, 2010). The participants involved in a dynamic complementarity setup during their performance of the second and third assignments twice received a message with encouraging feedback, that is, they had performed well and were encouraged to continue their work as a type of intrinsic incentive (Erasmus \& Schenk, 2008).

A decision-making structure was operationalized based on an allocation of the most important decisions to a software programmer. To investigate the effect of a centralized decision-making structure, the participants in a stable complementarity setup, at the beginning of the second and third assignments, received a message to not improvise on the assignment and not deviate from the specification. The participants involved in a dynamic complementarity setup with a decentralized decision-making structure received a message to feel free to improvise in the assignment at the beginning of the second and third assignments.

The actual time the participants spent to develop a product and the completeness and correctness of the assignments were the key measures of individual productivity. The rationale for choosing these metrics is presented in greater detail in the following section.

\subsection{Dependent Measures}

The primary dependent variables in this study considered two major dimensions of subjects' performance: quantity and quality. A quantitative dimension of productivity in software engineering is characterized by the change in the quantity of a developed product for a given period of time, and a qualitative dimension refers to the quality of the software product (Duncan, 1988). The output metric (the unit of product) is a challenging construct in software development; thus, attention is devoted to the input part of the productivity ratio.

The input effort is usually a sum of resources used to produce output. In software development, the main part of resources is a programmer's time spent working on software product development (Canfora et al., 2007). Therefore, the time taken by the participants to complete the assignment was used to characterize a quantitative dimension of the productivity metric.

Developed software products must fulfill concrete qualitative requirements because the qualitative aspect may explain the difference in time spent to complete a task. In this study, the final product quality was examined. Application quality can be examined from different perspectives, for example, the number of defects in the application or how well the application satisfies end-users (Edberg \& Bowman, 1996). Completeness and correctness (Tomaszewski \& Lundberg, 2005) of the application developed (how many of the animation requirements are correctly implemented and how well) was used because it is the most significant and appropriate in the experimental settings.

\subsection{Participants}

The participants were recruited through two crowdsourcing platforms: Microworkers https://microworkers.com) and Prolific.ac services (https://prolificac. zendesk.com/hc/en-us). The experiment was open to participants familiar with the Java, C, and Python languages. There was no restriction on gender, age, nationality, education, and prior programming experience. The experiment was available online, and 2,192 visitors visited the website: 1,196 (55\%) completed the questionnaire but did not begin the experiment; 398 (18\%) completed session 1; 71 (3\%) completed session 2; and 527 (24\%) submitted all experimental assignments as completed. From the completed, submitted assignments, 414 were rejected because the submissions did not fulfill the minimum requirements for the submission acceptance (unreasonable time and poor quality of the assignments). Thus, 113 (5\%) of the initial 2,192 visitors completed the experiment. Of the 113 participants that completed the experiment, three 
had an adaptive cognitive style, and we excluded those three from the analysis.

The initial sample size comprised 110 participants with an innovative cognitive style: 44 innovators were involved in a stable complementarity setup and 66 in a dynamic complementarity setup. A repeated-measures analysis of variance (ANOVA) was an appropriate statistical approach to identify the effect of complementarity setups on the individual productivity of software programmers. In this approach, however, unequal sample sizes can affect the homogeneity of the variance assumption when the difference between sample sizes is large (Keppel, 1991). To provide an accurate p value, sample sizes were balanced by randomly selecting 44 observations out of the 66 innovators involved in a dynamic complementarity setup. The final sample size comprised 88 observations, that is, 44 innovators involved in each of the stable and dynamic complementarity setups. An a priori power analysis with a power of 0.80 (Cohen, 1992) and an alpha of 0.05 demonstrated that a sample size of 28 observations was required to detect a medium effect size (0.25). Hence, we expected a significant difference between groups with the final sample size of 88 (44 in each group) observations. The descriptive statistics are presented in Table 4.

The participants were $80 \%$ male and aged on average 28 years. Thirty-five participants had a bachelor's degree 35 (39.8\%), 23 (26.1\%) had a high school education, and $22(25.0 \%)$ had a master's degree. Thirty participants $(34.1 \%)$ reported up to 5 years of programming experience, and $27(30.7 \%)$ up to 10 years of programming experience. Thirty-nine $(44 \%)$ participants used JavaScript regularly, and 4 (4.5\%) were experts in this programming language.

\section{Analysis and Results}

The data collected were regarding software programmers with an innovative cognitive style, and a $2 \times 3$ mixed design with repeated measures was appropriate to test the effect of complementarity setups on individual productivity. The first factor was the complementarity setup with two levels: stable and dynamic. The second factor was time with three levels: t1 - pretest (baseline) before introducing an aligned IT system, t2 - posttest after the implementation of an aligned IT system and complementarity setups, and t3 - follow-up to account for the learning effect. Time and quality (completeness and correctness) of the developed products was measured at all three times. Time and quality of the developed software were not significantly correlated; therefore, both dependent variables were analyzed with repeated-measures ANOVAs.

In general, after the data collection process, we expected that individuals with an innovative cognitive style would be more productive when involved in a dynamic, rather than stable complementarity setup. We also expected that the productivity scores for participants involved in both complementarity setups may increase for time scores and decrease for quality scores during the second session while learning an aligned IT system. Eventually, we expected that in the third session, software programmers with an innovative cognitive style would be more productive when matched with a dynamic, rather than stable complementarity setup. A summary of the expected and obtained results is presented in Table 5 .

The results from the online experiment demonstrated that, when completing the first assignment with a nonaligned IT system, time scores were significantly different for innovators involved in stable and dynamic complementarity setups (42 versus 33 minutes). Quality scores were significantly different for innovators involved in stable and dynamic complementarity setups (77 versus 63\%); however, quality per time is statistically nonsignificant for both groups of participants (1.83 versus $1.91 \% / \mathrm{min}$.).

As expected, when completing the second assignment with an aligned IT system, time scores increased for both groups; however, average assignment completion time increased by 7 minutes (16\%) for innovators involved in a stable complementarity setup and by 18 (54\%) minutes for innovators involved in a dynamic complementarity setup, compared with the baseline. The difference between the time scores for both groups of participants, however, became nonsignificant. Quality scores remained similar to the first assignment, and the difference between these scores was statistically significant (75\% versus 62\%, respectively). Quality per time unit became significantly higher for innovators involved in a stable complementarity setup, rather than in a dynamic complementarity setup (1.53 versus $1.22 \% / \mathrm{min}$., respectively). 
Table 4. Descriptive Statistics

\begin{tabular}{|c|c|c|c|c|c|c|}
\hline Factors & Value mapping & № & Min. & Max. & Mean & Std. dev. \\
\hline $\begin{array}{l}\text { Adaptive/innovative cognitive } \\
\text { style }\end{array}$ & $\begin{array}{l}\text { Theoretical mean } \\
96\end{array}$ & 88 & 97 & 141 & 111 & 9.807 \\
\hline Year born & Continuous value & 88 & 1967 & 1997 & 1988 & 6.944 \\
\hline Marital status & $\begin{array}{l}\text { 1-Single } \\
2 \text { - Married } \\
3 \text { - Divorced } \\
4 \text { - Separated } \\
5 \text { - Widowed }\end{array}$ & 88 & 1 & 3 & 1.27 & 0.473 \\
\hline Education & $\begin{array}{l}1 \text { - High School } \\
2 \text { - Associate } \\
3 \text { - Bachelor } \\
4 \text { - Master } \\
5 \text { - PhD }\end{array}$ & 88 & 1 & 5 & 2.7 & 1.176 \\
\hline $\begin{array}{l}\text { Experience in } \\
\text { programming }\end{array}$ & $\begin{array}{l}1 \text { - None or little } \\
2 \text { - Up to } 1 \text { year } \\
3-1-2 \text { years } \\
4-2-5 \text { years } \\
5-5-10 \text { years } \\
6 \text { - Over } 10 \text { years }\end{array}$ & 88 & 1 & 6 & 4.01 & 1.246 \\
\hline $\begin{array}{l}\text { Experience in } \\
\text { JavaScript }\end{array}$ & $\begin{array}{l}1 \text { - Never used } \\
2 \text { - Used only a few times } \\
3 \text { - Regular user } \\
4 \text { - Expert }\end{array}$ & 88 & 1 & 4 & 2.49 & 0.661 \\
\hline $\begin{array}{l}\text { Number of programming } \\
\text { languages }\end{array}$ & $\begin{array}{l}1 \text { - None } \\
2 \text { - Only one } \\
3 \text { - Two-three } \\
4 \text { - Four-five } \\
5 \text { - More than five }\end{array}$ & 88 & 1 & 5 & 3.7 & 0.899 \\
\hline
\end{tabular}


Table 5. Summary of Expected Versus Obtained Results

\begin{tabular}{|c|c|c|c|c|}
\hline Session & $\begin{array}{c}\text { Scores in } \\
\text { complementarity } \\
\text { setups }\end{array}$ & $p$ value & $\begin{array}{c}\text { Expected } \\
\text { results }\end{array}$ & $\begin{array}{c}\text { Obtained } \\
\text { results }\end{array}$ \\
\hline
\end{tabular}

Stable

(S)

Dynamic

Time, min.

1. Nonaligned IT system

2. Aligned IT system

3. Learning effect

Quality, \%

\section{Nonaligned IT system}

2. Aligned IT system

\section{Learning effect}

Quality per time (\% / min.)

1. Nonaligned IT system

\section{Aligned IT system}

3. Learning effect
42

49

47

77

75

73

1.83

1.53

1.55

\section{9}

(D)
47

45

33

51

0.454

0.567

$S>D$

$\mathrm{S}>\mathrm{D}$

$\mathrm{S}<\mathrm{D}$
$\mathrm{S}>\mathrm{D}$

63

62

0.002

$\mathrm{S}<\mathrm{D}$

$S>D$

61

0.032

$S<D$

$S>D$

$S>D$

1.9

1.22

0.026

$S<D$

$S>D$

1.36

0.156

$\mathrm{S}<\mathrm{D}$

$\mathrm{S}>\mathrm{D}$
The results demonstrate that compared with the second assignment, time scores decreased for the participants involved in both complementarity setups when performing the third assignment; however, average assignment completion time increased by 2 minutes (4\%) for innovators involved in a stable complementarity setup and by 6 minutes (12\%) for innovators involved in a dynamic complementarity setup, compared with the second assignment. Quality scores did not change significantly in a comparison with the second assignment ( $73 \%$ versus $61 \%$, respectively). The difference between quality per time became statistically nonsignificant for both groups of participants.

To demonstrate the accuracy and credibility of the obtained results, the types of validity and reliability issues addressed in the quantitative research were considered (Cook et al., 2002). To ensure conclusion validity, normality, homogeneity of between-group variance, homogeneity of variance-covariance matrices, and sphericity of within-group variance, the assumptions were not violated. The reliability of the treatment implementation was fixed on the developed website, the treatment did not change 
throughout the period of study, and the treatment was similarly applied to all the participants.

The threat of the construct validity such as hypotheses guessing (Cook et al., 2002) was minimized by not informing the participants about their cognitive style and complementary factors under investigation. The Hawthorne effect (Campbell \& Stanley, 2015) was minimized by using voluntary and anonymous participation. The threat of the experimenter expectancies was also minimized by the research designs. The internal validity of the study was ensured by a short duration of the experiment. External validity was also ensured by providing international access to the experimental website. Professionals who participated in the experiment enforced realism and representativeness of the target population.

\section{Discussion}

Increasing productivity has been and remains a major concern for many business sectors (Ajzen, 2011; Nagle, 2018), including software development organizations. In this experimental study, individual productivity, in terms of time and quality of the developed product, was compared when software programmers with innovative cognitive style were involved in two different complementarity setups (i.e., stable and dynamic) in a situation when a more aligned with the work process IT system was used.

Although the completeness of the experiment was disrupted, the results obtained in the study provide implications for the theory by addressing several issues. First, the study contributes to the literature that calls for investigations of the underlying factors of software programmer productivity (Chilton et al., 2005; de Barros Sampaio et al., 2010; Tonelli et al., 2013; Tomaszewski \& Lundberg, 2005; Trendowicz \& Münch, 2009). These studies have highlighted that productivity of an individual software programmer can be affected by factors including technology, task, personal, and organizational characteristics. Thus, this study contributed to this literature by demonstrating how these factors can be synchronized to increase individual programmer productivity.

Second, this study contributes to the literature that has investigated the underlying factors of individual knowledge worker productivity (Aral et al., 2012; Hopp et al., 2009; Palvalin et al., 2013).
These studies have reported an increasing need for research on underlying factors of individual knowledge worker productivity. The results showed that knowledge workers with innovative cognitive style have different performance, depending on the context of complementarities they interact with. Thus, the results of this study also contribute to the knowledge worker productivity literature because software programmers are an appropriate category of this type of workers (Hernández-López et al., 2015).

Third, in the first and third sessions, the innovators involved in a dynamic context worked faster but with a significantly lower quality than the innovators involved in a stable context who worked slower but generated a higher quality of the software product. The reason for this phenomenon could be that in a dynamic setup, the operational process was designed in a manner that provided fewer guidelines for programmers and shortened the time to perform the assignment, yet generated poorer quality. The difference in quality can also be caused by innovators' tendency to ignore the rules and avoid details (Kirton, 1994). Innovators involved in a dynamic context had a greater change in completion time when they learned an aligned IT system in the second session, but they learned this IT system faster than innovators involved in a stable context, as demonstrated in the third session. Additionally, the study demonstrated that the learning effect has just started; thus, the learning effect of using a new IT system requires more than two runs in the experiment.

Overall, the study showed that individuals with innovative cognitive style demonstrate different behavior and productivity when involved in stable versus dynamic complementarity setups and provided support for the systems approach of the complementarity theory (Milgrom \& Roberts, 1990, 1995), regarding how the use of IT systems may generate productivity gains at the level of an individual worker, by formulating and testing two differing and unique complementarity setups. In the literature on complementarities and their effect on individual IT-enabled productivity, only a limited number of factors have been investigated, including the IT system and work process (Aral et al., 2012; Athey \& Stern, 2002; Autor et al., 2003). Overall, all three studies provided incomplete results due to challenges 
in complementarities management and difficulties demonstrating the complementary effect between a limited number of factors (Porter \& Siggelkow, 2008). With complementarity setups developed by referring to the systems approach of the complementarity theory, we could overcome this limitation and materialize complementarities by applying a systems approach of the complementarity theory.

The results of this experiment enable managers to understand and investigate how complementary factors contribute to individual IT-enabled productivity. Understanding the impact of IT systems' use and factors supporting a successful deployment may be useful when planning the introduction and use of new IT systems. Our findings suggest that managers can more successfully implement and use an aligned IT system if they effectively capture complementary factors. Individual cognitive style, a work process structure, and specific human resource management practices were observed to be part of a mutually reinforcing cluster associated with higher individual IT-enabled productivity.

The results and insights of this study also provide recommendations for further research. First, during this online experiment, we realized that a greater number of runs are required before and after a more aligned IT system is used to obtain saturation in IT system learning and productivity data. Second, because data for only innovators was collected, further research can provide additional insights by studying individuals with adaptive cognitive style either in an online experiment or in a laboratory experiment with multiple runs that can provide high control over circumstances. Third, both productivity metrics (time and quality) must be closely monitored to understand the impact of complementarity setups and identify the optimal trade-off between them. Future experimental studies could reflect actual real-world practices by providing a more detailed consideration of complementarities.

\section{Conclusion}

Over the last decades, leaders in the area of organization economics have emphasized that an organization cannot be considered a black box anymore, and complementarities may play a critical role in increasing IT-enabled productivity.
Additionally, the literature that has investigated factors affecting knowledge worker productivity, including software programmer productivity, highlights the importance of the synergistic fit between different factors to increase IT-enabled productivity. Based on the systems approach of the complementarity theory, literature on cognitive style differences, and operational process structure and human resource management practices, two hypotheses were developed to assess, in an online experiment, the impact of stable and dynamic complementarity setups on individual productivity in a situation when a new, more aligned with the work process IT system was used in comparison with a less aligned IT system.

In this study, we were able to collect data mostly for innovators; therefore, the completeness of the experiment was disrupted. Yet, we were able to test how IT-enabled productivity of individuals with an innovative cognitive style is affected by stable and dynamic complementarity setups. Overall, the results suggest that software programmers with innovative cognitive style demonstrate different productivity outcomes when involved in either stable or dynamic complementarity setups and provide support to the systems approach of the complementarity theory.

Finally, to address limitations of this study, designs of further experiments should include a longer learning curve before and after a new IT system is introduced and used. Time and quality must be closely examined to understand the impact of the complementarity factors and optimal tradeoffs between them. More research is also required to investigate whether online work environments attract individuals with a particular cognitive style.

\section{References}

Abdolmohammadi, M., \& Wright, A. (1987). An examination of the effects of experience and task complexity on audit judgments. The Accounting Review, 62(1), 1-13.

Agor, W. H. (1984). Intuitive management. Englewood Cliffs, Prentice Hall.

Ahearne, M., Jelinek, R., \& Rapp, A. (2005). Moving beyond the direct effect of SFA adoption on salesperson performance: Training and support as key moderating factors. Industrial Marketing Management, 34(4), 379-388.

Ajzen, I. (2011). Job satisfaction, effort, and 
performance: A reasoned action perspective. Contemporary Economics, 5(4), 32-43.

Amabile, T. M. (1996). Creativity in context: Update to "the social psychology of creativity". Westview Press.

Amabile, T. M., Hill, K. G., Hennessey, B. A., \& Tighe, E. M. (1994). The work preference inventory: Assessing intrinsic and extrinsic motivational orientations. Journal of Personality and Social Psychology, 66(5), 950.

Antikainen, R., \& Lönnqvist, A. (2006). Knowledge work productivity assessment. Institute of Industrial Management. Tampere University of Technology. PO Box, 541, 79-102.

Aral, S., Brynjolfsson, E., \& van Alstyne, M. (2012). Information, technology and information worker productivity. Information System Research, 23(3), 849-867.

Arechar, A. A., Gächter, S., \& Molleman, L. (2018). Conducting interactive experiments online. Experimental Economics, 21(1), 99-131.

Armstrong, M. (2010). Armstrong's handbook of reward management practice: Improving performance through reward. Kogan Page Publishers.

Arvanitis, S., \& Loukis, E. N. (2009). Information and communication technologies, human capital, workplace organization and labor productivity: A comparative study based on firm-level data for Greece and Switzerland. Information Economics and Policy, 21(1), 43-61.

Athey, S., \& Stern, S. (2002). The impact of information technology on emergency health care outcomes. RAND Journal of Economics, 33, 339-432.

Autor, D. H., Levy, F., \& Murnane, R. J. (2003). The skill content of recent technological change: An empirical exploration. Quarterly Journal of Economics, 118(4), 1279-1333.

Axtell, C. M., Holman, D. J., Unsworth, K. L., Wall, T. D., Waterson, P. E., \& Harrington, E. (2000). Shopfloor innovation: Facilitating the suggestion and implementation of ideas. Journal of Occupational and Organizational Psychology, 73(3), 265-285.

Baer, M., Oldham, G. R., \& Cummings, A. (2003). Rewarding creativity: When does it really matter? Leadership Quarterly, 14, 569-586.

Berings, M. G. M. C., Poell, R. F., \& Simons, P. R. (2005). Conceptualizing on-the-job learning styles. Human Resource Development Review, 4, 373-400.

Birnbaum, M. H. (2004). Human research and data collection via the Internet. Annual Review of
Psychology, 55, 803-832.

Bloom, N., \& Van Reenen, J. (2011). Human resource management and productivity. In O. Ashenfelter \& D. Card (Eds.), New developments and research on labor markets: Handbook of labor economics (Vol. 4b, pp. 1697-1767). Elsevier.

Bloom, N., Sadun, R., \& van Reenen, J. (2010). Recent advances in the empirics of organizational economics. Annu. Rev. Econ., 2(1), 105-137.

Brown, L. L. (2001). Review of the Kirton adaptioninnovation inventory. In B. Plake \& J. Impara (Eds.), The fourteenth mental measurements yearbook (pp. 647-649). University of Nebraska Press.

Brynjolfsson, E., \& Hitt, L. (2003). Computing productivity: Firm-level evidence. Review of Economics and Statistics, 85, 793-808.

Brynjolfsson, E., \& Milgrom, P. (2013). Complementarity in organizations. In R. Gibbons \& J. Roberts (Eds.), The handbook of organizational economics (pp. 11-55). Princeton University Press.

Buchanan, T. (2002). Online assessment: Desirable or dangerous? Professional Psychology: Research \& Practice, 33, 148-154.

Bugamelli, M., \& Pagano, P. (2004). Barriers to investment in ICT. Applied Economics, 36, 22752286.

Camerer, C. F., \& Weber, R. A. (2013). Experimental organizational economics. In R. S. Gibbons \& J. Roberts (Eds.), The handbook of organizational economics (pp. 213-262). Princeton University Press.

Campbell, D. T., \& Stanley, J. C. (2015). Experimental and quasi-experimental designs for research. Ravenio Books.

Canfora, G., Cimitile, A., Garcia, F., Piattini, M., \& Visaggio, C. A. (2007). Evaluating performances of pair designing in industry. Journal of Systems and Software, 80(8), 1317-1327.

Cequea, M. M., Monroy, C. R., \& Bottini, M. A. N. (2011). The productivity from a human perspective: Dimensions and factors. Intangible Capital, 7(2), 549-584.

Chilton, M. A., Hardgrave, B. C., \& Armstrong, D. J. (2005). Person-job cognitive style fit for software developers: The effect on strain and performance. Journal of Management Information Systems, 22(2), 193-226.

Chung, K., \& Hossain, L. (2009). Measuring performance of knowledge-intensive workgroups through social networks. Project Management Journal, 40(2), 34-58. 
Cohen, J. (1992). A power primer. Psychological Bulletin, 112(1), 155-159.

Cook, T. D., Campbell, D. T., \& Shadish, W. (2002). Experimental and quasi-experimental designs for generalized causal inference. Houghton Mifflin.

Dandurand, F., Shultz, T. R., \& Onishi, K. H. (2008). Comparing online and lab methods in a problemsolving experiment. Behavior Research Methods, 40(2), 428-434.

de Barros Sampaio, S. C., Barros, E. A., de Aquino Junior, G. S., de Silva, M. J. C., \& de Lemos Meira, S. R. (2010, August). A review of productivity factors and strategies on software development. In Software Engineering Advances (ICSEA), 2010 Fifth International Conference on (pp. 196-204). IEEE.

Dedrick, J., Kraemer, K. L., \& Shih, E. (2013). Information technology and productivity in developed and developing countries. Journal of Management Information System, 30(1), 97-122.

Drucker, P. F. (1999). Knowledge-worker productivity: The biggest challenge. California Management Review, 41(2), 79-94.

Duncan, A. S. (1988). Software development productivity tools and metrics. Proceedings from the 10th International Conference on Software Engineering. IEEE, Computer Society Press, 4148.

Edberg, D. T., \& Bowman, B. J. (1996). User-developed applications: An empirical study of application quality and developer productivity. Journal of Management Information Systems, 13(1), 167-185.

Edwards, J. R. (1991). Person-job fit: A conceptual integration, literature review and methodological critique. International Review of Industrial and Organizational Psychology, 6, 283-357.

Ennen, E., \& Richter, A. (2010). The whole is more than the sum of its parts - or is it? A review of the empirical literature on complementarities in organizations. Journal of Management, 36(1), 207-233.

Erasmus, B., \& Schenk, H. (2008). South African human resource management: Theory \& practice. Juta and Company Ltd.

Foss, N. J. (2005). Strategy and economic organization in the knowledge economy. Oxford: Oxford University Press.

Frey, B. S., \& Osterloh, M. (2002). Successful management by motivation: Balancing intrinsic and extrinsic incentives. Berlin, Heidelberg, New York: Springer.

Gibbons, R., \& Roberts, J. (Eds.). (2013). The handbook of organizational economics. UK: Princeton University Press.

Graziotin, D., Wang, X., \& Abrahamsson, P. (2014). Happy software developers solve problems better: Psychological measurements in empirical software engineering. PeerJ, 2, e289.

Gupta, A., Kannan, K., \& Sanyal, P. (2018). Economic experiments in Information Systems. Management Information Systems Quarterly, 42(2), 595-606.

Han, K., Chang, Y. B., \& Hahn, J. (2011). Information technology spillover and productivity: The role of information technology intensity and competition. Journal of Information Technology, 23(3), 185-202.

Hayes, J., \& Allinson, C. W. (1998). Cognitive style and the theory and practice of individual and collective learning in organizations. Human Relations, 51, 847-871.

Hernández-López, A., Colomo-Palacios, R., SotoAcosta, P., \& Lumberas, C. C. (2015). Productivity measurement in software engineering: A study of the inputs and the outputs. International Journal of Information Technologies and Systems Approach (IJITSA), 8(1), 46-68.

Hewson, C., \& Stewart, D. W. (2016). Internet research methods. In: P. Brandimarte, M. Davidian, B. Everitt, G. Molenberghs, W. Piegorsch, \& F. Ruggeri (Eds.), Statistics reference online (pp. 1-6). Wiley.

Hitt, L. M., \& Brynjolfsson, E. (1997). Information technology and internal firm organization: An exploratory study. Journal of Information Systems, 14(2), 81-101.

Hopp, W. J., Iravani, S. M., \& Liu, F. (2009). Managing white-collar work: An operations-oriented survey. Production and Operations Management, 18(1), 1-32.

$\mathrm{Hu}$, Q., \& Quan, J. (2005). Evaluating the impact of IT investments on productivity: A causal analysis at industry level. International Journal of Information Management, 25, 39-53.

Hunt, R. G., Krzystofiak, F. J., Meindl, J. R., \& Yousry, A. M. (1989). Cognitive style and decision making. Organizational Behavior and Human Decision Processes, 44(3), 436-453.

Jain, V., \& Kanungo, S. (2005). Beyond perceptions and usage: Impact of nature of information systems use on information system-enabled productivity. International Journal of Human-Computer Interaction, 19(1), 113-136.

Jain, V., \& Kanungo, S. (2013). Realizing IT value: Post adoptive IS usage and performance impacts at 
individual level. International Journal of Business Information Systems, 14(2), 202-222.

Jiang, Z., Naudé, P., \& Comstock, C. (2007). An investigation on the variation of software development productivity. International Journal of Computer, Information, and Systems Sciences, and Engineering, 1(2), 72-81.

Jorgenson, D. W. (2007). Information technology and the G7 economies. In U. Apte \& U. Karmarkar (Eds.), Managing in the information economy (Vol. 1, pp. 29-57). Springer Science + Business Media, LLC.

Kasof, J., Chen, C., Himsel, A., \& Greenberger, E. (2007). Values and creativity. Creativity Research Journal, 19(2-3), 105-122.

Keen, P. G., \& Scott-Morton, M. (1978). Decision support systems: An organizational perspective. Addison-Wesley.

Keppel, G. (1991). Design and analysis: A researcher's handbook. Prentice-Hall, Inc.

Kianto, A., Shujahat, M., Hussain, S., Nawaz, F., \& Ali, M. (2018). The impact of knowledge management on knowledge worker productivity. Baltic Journal of Management, https:// doi.org/10.1108/BJM12-2017-0404

Kirton, M. (1976). Adaptors and innovators: A description and measure. Journal of Applied Psychology, 61(5), 622-629.

Kirton, M. J. (1994). Adaptors and innovators. Routledge.

Kirton, M. J. (2003). Adaption-innovation: In the context of diversity and change. Routledge.

Kock Jr, N. F., \& McQueen, R. J. (1996). Product flow, breadth and complexity of business processes: An empirical study of 15 business processes in three organizations. Business Process Re-engineering \& Management Journal, 2(2), 8-22.

Kohli, R., \& Grover, V. (2008). Business value of IT: An essay on expanding research directions to keep up with the times. Journal of the AIS, 9(1), 23-37.

Kozlowski, S. W. J., \& Bell, B. S. (2003). Work groups and teams in organizations. In W. C. Borman, D. R. Ilgen, \& R. J. Klimoski (Eds.), Comprehensive handbook of psychology (Vol. 12, pp. 333-375). Wiley.

Kristof-Brown, A. L., \& Guay, R. P. (2011). Personenvironment fit. In S. Zedeck (Ed.), American Psychological Association handbook of industrial and organizational psychology (Vol. 3, pp. 1-50). Washington, DC: American Psychological Association.

Kristof, A. L. (1996). Person-organization fit: An integrative review of its conceptualizations, measurement, and implications. Personnel Psychology, 49(1), 1-49.

Leoni, R. (2013). Organization of work practices and productivity: an assessment of research on world-class manufacturing. In A. Grandori (Ed.), Handbook of economic organization. Integrating economic and organization theory (pp. 312-334). Edward Elgar.

MacCormack, A., Verganti, R., \& Iansiti, M. (2001). Developing products on "Internet time": The autonomy of a flexible development process. Management Science, 47(1), 133-150.

Mason, R. O., \& Mitroff, I. I. (1973). A program for research on management information systems. Management Science, 19(5), 475-487.

McLeod, A., Clark, J., Warren, J., \& Dietrich, G. (2008). - The impact of information systems on end user performance: Examining the effects of cognitive style using learning curves in an electronic medical record implementation. Communications of the Association for Information Systems, 22, pp. 165-184.

Milgrom, P., \& Roberts, J. (1990). The economics of modern manufacturing: Technology, strategy, and organization. American Economic Review, 80(3), 511-528

Milgrom, P., \& Roberts, J. (1995). Complementarities and fit: Strategy, structure, and organizational change in manufacturing. Journal of Accounting and Economics, 19, 179-208.

Morgeson, F. P., \& Humphrey, S. E. (2006). The work design questionnaire (WDQ): Developing and validating a comprehensive measure for assessing job design and the nature of work. Journal of Applied Psychology, 91, 1321-1339.

Muratbekova-Touron, M., \& Galindo, G. (2018). Leveraging psychological contracts as an HR strategy: The case of software developers. European Management Journal.

Nagle, F. (2018). Open source software and firm productivity. Management Science.

Oldham, G. R., \& Cummings, A. (1996). Employee creativity: Personal and contextual factors at work. Academy of Management Journal, 39(3), 607-634.

Palvalin, M., Lönnqvist, A., \& Vuolle, M. (2013). Analysing the impacts of ICT on knowledge work productivity. Journal of Knowledge Management, 17(4), 545-557.

Parmigiani, A., \& Mitchell, W. (2009). Complementarity, capabilities, and the boundaries of the firm: The impact of within- 
firm and inter-firm expertise on concurrent sourcing of complementary components. Strategic Management Journal, 30(10), 1065-1091.

Porter, M., \& Siggelkow, N. (2008). Contextuality within activity systems and sustainability of competitive advantage. The Academy of Management Perspectives, 22(2), 34-56.

Pyöriä, P. (2005). The concept of knowledge work revisited. Journal of knowledge management, 9(3), 116-127.

Reinhardt, W., Schmidt, B., Sloep, P., \& Drachsler, H. (2011). Knowledge worker roles and actions results of two empirical studies. Knowledge and Process Management, 18(3), 150-174.

Reips, U.-D. (2002). Standards for Internet-based experimenting. Experimental Psychology, 49, 243-256.

Roberts, J. (2007). The modern firm: Organizational design for performance and growth. Oxford University Press.

Rowe, A. J., \& Boulgarides, J. D. (1992). Managerial decision-making: A guide to successful business decision. Macmillan.

Rowe, A. J., \& Mason, R. O. (1987). Managing with style. San Francisco: Jossey-Bass.

Sadler-Smith, E., \& Smith, P. J. (2004). Strategies for accommodating individuals' styles and preferences in flexible learning programs. British Journal of Educational Technology, 35, 395-412.

Schumpeter, J. A. (1909). On the concept of social value. The Quarterly Journal of Economics 23(2), 213-232.

Singh, R., \& Mohanty, M. (2012). Impact of training practices on employee productivity: A comparative study. Interscience Management Review (IMR), 2(2), 74.

Sliwa, J. (2018). Environment, people, and time as factors in the Internet of Things technical revolution. Internet of Things A to Z: Technologies and Applications, 51-76.

Solow, R. (1987). We'd better watch out. New York Times Book Review, July 12, 36.

Staniewski, M. (2011). Management of human resources in the aspect of innovativeness. Contemporary Economics, 5(1), 84-91.

Tambe, P., Hitt, L. M., \& Brynjolfsson, E. (2012). The extroverted firm: How external information practice affect innovation and productivity. Management Science, 58(5), 843-859.

Tomaszewski, P., \& Lundberg, L. (2005). Software development productivity on a new platform: An industrial case study. Information and Software
Technology, 47(4), 257-269.

Tonelli, A. O., Bermejo, P. H. S., Santos, M. A., Zambalde, A. L., de Oliveira, M. S., \& Antonialli, L. M. (2013, January). Agile practices to accelerate the delivery of software: a quantitative study with software professionals. In System Sciences (HICSS), 2013 46th Hawaii International Conference (pp. 4771-4779). IEEE.

Trendowicz, A., \& Münch, J. (2009). Factors influencing software development productivity - state-of-the-art and industrial experiences. Advances in Computers, 77, 185-241.

Webster, M. (2012). Bridging the information worker productivity gap: New challenges and opportunities for it. IDC Information and Data.

Wojtczuk-Turek, A. (2017). In search of key HR practices for improvement of productivity of employees in the KIBS sector. Contemporary Economics, 11(1), 5-15.

Womer, N. (1984). Estimating learning curves from aggregate monthly data. Management Science, 30(8), 982-992.

Wu, L., Lin, C-Y., Aral, S., \& Brynjolfsson, E. (2009). Value of social network - A large-scale analysis on network structure impact to financial revenue of information technology consultants. Paper presented at the 2009 Winter Conference on Business Intelligence, February 26-28, 2009; Salt Lake City, UT.

Zabojnik, J. (2002). Centralized and decentralized decision making in organizations. Journal of Labor Economics, 20(1), 1-22. 